\title{
Back to school after Covid-19 lockdown in Brazil
}

Alberto $\mathrm{Abad}^{1}$

Thaís Marques $\mathrm{Abad}^{2}$

\author{
${ }^{1}$ Psychology Postgraduate Programme, Federal University of Juiz de Fora (UFJF), Juiz de Fora, MG, \\ Brazil. E-mail: alberto.abad@ich.ufjf.br \\ ${ }^{2}$ Federal University of Pará (UFPA), Belém, PA, Brazil. E-mail: tmabad74@gmail.com
}

\begin{abstract}
South America has become the new epicenter of the coronavirus, especially in Brazil where the disease continues to spread exponentially across the country. This text aims to analyze the psychosocial factors of Covid-19 on back to school strategies in Brazil from a bioecological perspective. At the microsystem level, the population is experiencing different levels of stress and fear; at the microsystem level, changes in routines, separation from family and friends, and closure of schools; and at the macrosystem level, national guidelines to control the pandemic, institutional standards on a national and international scale. Therefore, the main focus for the success of school return must be in the prevention of contagion and with physical and psychological health, and should not only consider the demands of curricula, financial or administrative management. For this reason, it is paramount that greater female representativeness is increased in decision-making levels of the meso and macrosystem, regarding the resumption of school and academic activities in the pandemic period, since the number of female leaders in decision-making, is still insufficient.
\end{abstract}

Keywords: Covid-19; bioecological perspective, back to school.

\section{Introduction}

South America has become the new epicenter of the coronavirus, especially in Brazil where the disease continues to spread exponentially across the country; on the date of writing this article Brazil sums up more than one and a half million confirmed cases and sixty thousand deaths. As Brazil has not yet reached the peak of the pandemic (WHO, 2020), from a bioecological perspective, the psychosocial impacts of Covid-19 could be viewed at different levels of analysis: at the microsystem level, the population is experiencing different levels of stress and fear as the pandemic has disrupted lives, triggered public panic, and changed the routine (Bao et al., 2020), affecting not only physically but also psychologically (Abad et al., 2020a; Jahanshahi et al., 2020; Jia et 
al., 2020; Li et al., 2020; Qiu et al., 2020); at the microsystem level, changes in routines, separation from family and friends, closure of schools, etc. (Zhang et al., 2020); and at the macrosystem level, national guidelines to control the pandemic, institutional standards on a national and international scale (Smith, 2019; Taylor, 2019; Bao et al., 2020).

This text aims to analyze the psychosocial factors of Covid-19 on back to school strategies in Brazil from a bioecological perspective. Based on that, different levels of analysis will be considered: at the microsystem level, the population is experiencing different levels of stress and fear; at the microsystem level, changes in routines, separation from family and friends, and closure of schools; and at the macrosystem level, national guidelines to control the pandemic, institutional standards on a national and international scale.

\section{Methods}

The proposed methodology is of a descriptive type supported by bibliographic research, which included books and periodical publications that address the current studies on psychosocial factors of Covid-19 disease. To achieve the objective, the ERIC (https://eric.ed.gov/) and Web of Science (www.webofknowledge.com) databases were chosen, as well as PsycNET (https: //psycnet.apa.org). These sources of information were chosen for their relevance to the areas of Education and/or Psychology. The main original publications were read and analyzed. To access these texts, electronic searches were performed in important sources of information for the areas of Education and Psychology, such as: Institutional Repository UFJF, PsycINFO, Fundación Dialnet, Educational Resources Information Center (ERIC, Institute of Education Sciences) and Google Scholar.

\section{Discussion}

From a macrosystem view, Brazil faces the health crisis in a delicate social, economic and political context characterized by a lack of national leadership that offers clear guidelines to control the pandemic (the president minimizing the pandemic as a "little flu", absence of a Minister of Health with technical knowledge of health, lack of doctors in key positions in the Ministry of Health, conflicting and contradictory messages from government spokespersons related to the impact and severity of the pandemic, use of medications not recommended by the World Health Organization 
(WHO) (Chloroquine and Hydroxychloroquine), shortages of basic inputs for the patient care, etc. increasing the rates of contagion and weakening the Brazilian Health System.

At this juncture, each State of the Federation had to face the challenges of Covid-19 with local strategies, primarily related to hospital care, social distance indexes, the lockdown of the population and closing of commercial, religious, school and academic institutions (mesosystem) - mostly without support from the Federal Government and out of sync with other States and regions.

Lockdown and School closure have been useful measures of pandemic control at national and international levels, however, there is substantial evidence that the transmission of the infection has increased again in several countries after its reopening, which leads to the belief that there is no of a consensus between governments and technical health professionals on what would be the appropriate time for this reopening (Viner et al., 2020). Furthermore, lockdown (mesosystem) has possibly contributed to the development of psychological or cognitive disorders (microsystem) such as depression, anxiety, fear, anger, mood swings, changes in appetite, and insomnia in part of the population (Abad et al., 2020a).

Consequently, planning for the reopening of schools, besides considering the prevention of contagion should also focus on the psychological health of professionals and the target audience of education. It is pivotal that reopening strategies consider the appropriate methods that the WHO uses to control the spread of infection, since there are still no specific vaccines or antiviral therapies for Covid-19 (WHO, 2008). Schools must also count on with: health professionals and building and logistics structure that brings together favorable hygiene conditions; not all Brazilian public schools have such adequate structures, like many, due to the lack of sanitary structure, have difficulties in controlling daily contagions such as chickenpox, flu, and even simple pediculosis control.

We have identified several macro and mesosystem mental risk factors related to the return to school of education professionals. The first, (mesosystem factor) is related to the overload of online work during the pandemic and the burn-out syndrome (Afonso \& Figueira, 2020) as a significant portion of this group continued to work at home during compulsory confinement, developing their usual work activities and carrying out new activities linked to digital inclusion, causing a work overload at a time 
when several of these professionals were forced to link their pedagogical functions to domestic tasks carried out more frequently than usual to avoid spreading the disease in the home environment. All these tasks developed amid a health, economic, political and social crisis (macrosystem factor) that are undoubtedly inducing physical and mental exhaustion, and eventually triggering the burn-out syndrome.

In Brazilian research that aimed to assess peri-traumatic stress (CPDI Scale), and fear (FCV-19S Scale) of the Brazilian population during lockdown (Abad et al., $2020 \mathrm{~b}$ ), researchers concluded that gender roles are essential to analyze psychological reactions during the pandemic, on both scales, the average scores of women were higher; this finding is psychologically significant because, although women and men are analogous in many ways, it reflects the cognitive and behavioral differences of the genders that influence how health care related to manifestation, epidemiology and pathology is approached (Regitz-Zagrosek, 2020).

The female gender is conceived as more aware of the importance of medical assistance and more adherent to health counseling and treatment (Rugema et al., 2020). In this sense, due to social gender constructs, male gender might not openly express his fears of Covid-19 and does not follow the preventive health recommendations that WHO determines to manage the spread of coronavirus infection (WHO, 2008), that is, minimize the risks of the pandemic and do not follow hygiene and social detachment practices.

In the study, the highest female scores in the scales were exhaustion and attention deficit, results that agree with the fact that women often assume most of the burden and risk of health care and hygiene (Smith, 2019), protection, educational and emotional assistance for children, assistance, and care for their parents, spouses, and friends - usually with little intra and extra family support. Besides, the closure of schools, during mandatory confinement, has a differential effect for the female gender specifically for education professionals - since they frequently carry out the monitoring and educational guidance both in their families (Smith, 2019) and of their students.

Therefore, the return to face-to-face classes for many teachers means both the fear of being infected or infecting their family and social circle, as well as uncertainty and concern about adapting to the pedagogical strategies after the schools reopened and fulfilling more strenuous working hours. In these conditions, how emotionally do these professionals get in the current scenario? These workers are usually more subject to 
progressive deterioration of their physical and mental health (Martins, 2007) both before and during the pandemic, so it is not uncommon for them to have emotional and psychosomatic illnesses arising from working conditions (stress, irritability, lack of sleep, eating disorders, among others), it is even observed that these professionals are among those with the highest incidence of cases of the burn-out syndrome (Afonso \& Figueira, 2020).

The emotional health of education professionals is directly related to the good performance of their work functions in the reopening of school units, especially during the pandemic. It is worth mentioning that students also share the same effects of confinement (anxiety, fear, stress, and exhaustion), so these implications can influence, as well as their teachers, the behavior that will act on the return to school. Fear of contagion can even determine whether they want to or their parents allow them to return to face-to-face classes. Thus, for the mesosystem, the return of students represents a challenge, since they must adapt to new behavioral learning: correct use and hygiene of protective masks and the habit of social distancing, frequent care with personal hygiene, constant asepsis of materials and personal objects used in the school environment, avoid sharing personal objects and school materials.

However, another portion of students will represent an even greater challenge for returning to face-to-face classes, the students are the target audience of Special Education (disabilities, global developmental disorders, gifted and talented children) since they are people with specific behavior patterns and routines that are likely to present many difficulties and resistance to the adaptation to new pandemic control protocols. Such students should not have their needs neglected during the reopening of face-to-face classes, so specific strategies must be devised to meet this demand since the legal provisions advocate an inclusive education to be respected even in pandemic times. These new behaviors are a challenge, since children and adolescents, from LatinAmerican countries and especially from the northern region of Brazil are culturally accustomed to physical contact.

To avoid this work overload and possible failure of the school reopening motivated by an increase in the number of cases of Covid-19 in Brazil and Latin American countries, leading again to the closure of educational institutions, it will be essential that each school unit has at least one professional of fixed health in each shift (psychologist, health agent, medical school or nursing student) and that the 
responsibility for the risks or the success of the return to face-to-face classes do not rest solely under the tutelage of education professionals, who historically have already suffered work, emotional and financial overloads - worsened since the beginning of cases of contagion by the coronavirus.

\section{Conclusion}

The main focus for the success of school return must be in the prevention of contagion and with physical and psychological health, and should not only consider the demands of curricula, financial or administrative management. It is possible to infer that it is extremely important to make decisions related to school return, which protect students, control the spread of infection, and, consequently, improve the overall mental health (Wenham, Smith \& Morgan, 2020). For this reason, it is paramount that greater female representativeness is increased in decision-making levels of the meso and macrosystem, regarding the resumption of school and academic activities in the pandemic period since the number of female leaders in decision-making is still insufficient. Decisions on public policy issues in the field of education and health at this crucial moment in which the country lives. In short, women in general, and teachers in particular, for their roles in society, are in a strategic position to improve interventions, equitable policies and new approaches to control the Covid-19 pandemic.

\section{References}

Abad, A. , da Silva, J. , das Neves Braga, J. , Medeiros, P. , de Freitas, R. , Coimbra, N. and da Silva, J. (2020a). Preparing for the COVID-19 Mental Health Crisis in Latin America-Using Early Evidence from Countries that Experienced COVID-19 First. Advances in Infectious Diseases, 10, 40-44. https://doi.org/10.4236/aid.2020.103005 Abad, Almeida da Silva, Teixeira, Mármora, Monteiro Campos, Paiva, Bastos, Antonelli-Ponti, de Freitas \& Da Silva. (2020b in press). Evaluation of Fear and Peritraumatic Distress in Brazil during Covid-19.

Afonso, P., \& Figueira, L. (2020). Pandemia COVID-19: Quais são os Riscos para a Saúde Mental?. Revista Portuguesa de Psiquiatria e Saúde Mental, 6(1), 2-3

Bao, Y., Sun, Y., Meng, S., Shi, J., \& Lu, L. (2020). Covid-19 epidemic: address mental health care to empower society. The Lancet, 395(10224), e37-e38. 
Jahanshahi, A. A., Dinani, M. M., Madavani, A. N., Li, J., \& Zhang, S. X. (2020). The distress of Iranian adults during the Covid-19 pandemic-More distressed than the Chinese and with different predictors. medRxiv. https://doi.org/10.1016/j.bbi.2020.04.081

Jia, R., Ayling, K., Chalder, T., Massey, A., Broadbent, E., Coupland, C., \& Vedhara, K. (2020). Mental health in the UK during the COVID-19 pandemic: early observations. medRxiv. https://doi.org/10.1101/2020.05.14.20102012

Li, S., Wang, Y., Xue, J., Zhao, N., \& Zhu, T. (2020). The impact of COVID-19 epidemic declaration on psychological consequences: a study on active weibo users. International Journal of Environmental Research and Public Health, 17(6), 2032. https://doi.org/10.3390/ijerph17062032

Martins, M. D. G. T. (2007). Sintomas de stress em professores brasileiros. Revista Lusófona de Educação, (10), 109-128.

Qiu, J., Shen, B., Zhao, M., Wang, Z., Xie, B., \& Xu, Y. (2020). A nationwide survey of psychological distress among Chinese people in the COVID-19 epidemic: implications and policy recommendations. General psychiatry, 33(2). https://doi.org/10.1136/gpsych-2020-100213

Regitz-Zagrosek, V. (2012). Sex and gender differences in health. EMBO reports, 13(7), 596-603. https://doi.org/10.1038/embor.2012.87

Rugema, L., Persson, M., Mogren, I., Ntaganira, J., \& Krantz, G. (2019). A qualitative study of healthcare professionals' perceptions of men and women's mental healthcare seeking in Rwanda. Journal of Community Psychology. https://doi.org/10.1002/jcop.22308

Smith J. (2019). Overcoming the "tyranny of the urgent": integrating gender into disease outbreak preparedness and response. Gender Develop 2019; 27: 355-69. https://doi.org/10.1080/13552074.2019.1615288

Taylor, S. (2019). The Psychology of Pandemics: Preparing for the Next Global Outbreak of Infectious Disease. Cambridge Scholars Publishing: UK.

Viner, R., et al. (2020). School closure and management practices during coronavirus outbreaks including COVID-19: a rapid systematic review. The Lancet Child \& Adolescent Health. https://doi.org/10.1016/S2352-4642(20)30095-X 
Wenham, C., Smith, J., \& Morgan, R. (2020). COVID-19: the gendered impacts of the outbreak. The Lancet, 395(10227), 846-848. https://doi.org/10.1016/S01406736(20)30526-2

World Health Organization. (2008). WHO outbreak communication planning guide. Geneva.

World Health Organization. (2020). Coronavirus disease (COVID-19). Situation Report - $153 . \quad$ https://www.who.int/docs/default-source/coronaviruse/situationreports/20200621-covid-19-sitrep-153.pdf?sfvrsn=c896464d_2

Zhang, S. X., Wang, Y., Rauch, A., \& Wei, F. (2020). Unprecedented disruption of lives and work: Health, distress and life satisfaction of working adults in China one month into the COVID-19 outbreak. Psychiatry research, 112958. https://doi.org/10.1016/j.psychres.2020.112958 